Lepr Rev (1996) 67, 318-324

\title{
The pattern of cataract and the postoperative outcome of cataract extraction in Ethiopian leprosy patients as compared to nonleprosy patients
}

\author{
T. GIRMA, F. MENGISTU \& M. HOGEWEG* \\ Ophthalmic Department of The All Africa Leprosy and \\ Rehabilitation Training Centre, PO Box 165, Addis Ababa, Ethiopia; \\ *Netherlands Leprosy Relief Association, Spoorsingel 95, 2613 BC \\ Delft, Netherlands
}

\section{Accepted for publication 13 February 1996}

\begin{abstract}
Summary Cataract is a blinding disease occuring all over the world. One of the causes of cataract is leprosy.

Sixty leprosy and 100 nonleprosy patients were assessed and underwent intracapsular cataract extraction.

Leprosy patients with cataract were much younger than nonleprosy patients. The leprosy group had a significantly higher rate of complications and this was seen more in paucibacillary cases. There was a higher rate of visual disability in the leprosy group than in the nonleprosy group.

Cataract was seen in younger patients in the leprosy group. This raised the possibility of leprosy being the cause of the cataract. The leprosy group consisted mostly of multibacillary cases, however unlike in other studies the rate of complications tended to be higher in the paucibacillary group. There were no preoperative findings that correlated with a low postoperative intraocular pressure.
\end{abstract}

\section{Introduction}

Around 250,000 people in the world are blind from leprosy. One of the causes of blindness in leprosy is cataract. ${ }^{1}$ Cataract is the leading cause of blindness in the developing world, ${ }^{2}$ and has several causes in leprosy. It can be due to repeated inflammations, $\mathrm{age}^{3}$ or steroid treatment, which is frequently used in the treatment of reactions in leprosy. Leprosy has also been incriminated as the cause of cataract. ${ }^{4}$

Cataract extraction in leprosy patients is said to be associated with a higher risk of complications. The anatomical changes due to repeated inflammations or infiltrations are said to be associated with intraoperative and postoperative complications. ${ }^{5}$ Leprosy patients have a lower intraocular pressure when compared to nonleprosy patients. This is said to be due to atrophy of the ciliary body as a result of repeated inflammation, 


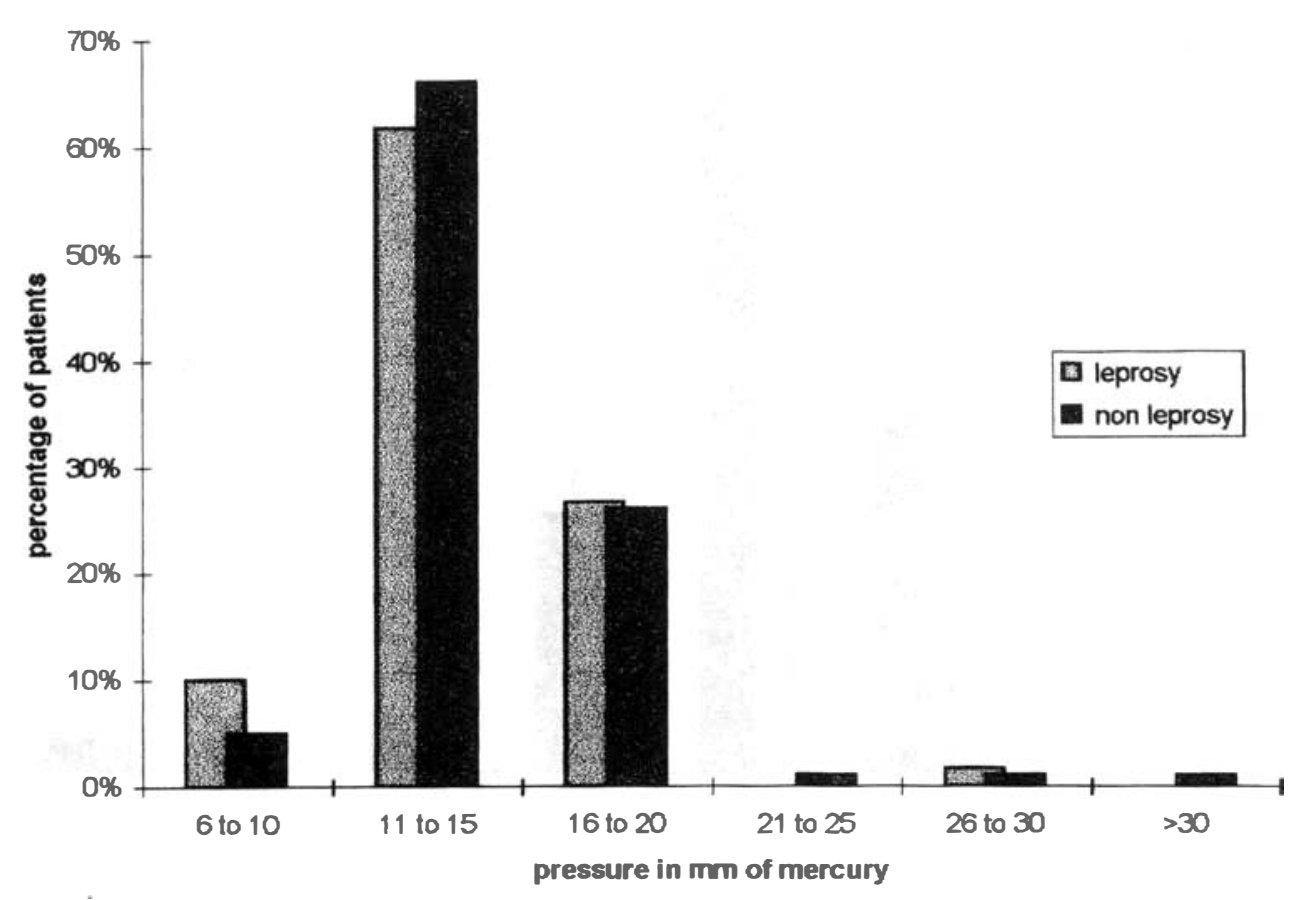

Figure 1. Pre-operative intraocular pressures of leprosy and nonleprosy patients.

resulting in a decreased production of aqueous humour. ${ }^{5}$ The other speculation is that leprosy patients tend to have damage to the autonomic nerves that supply the eye. Changes in intraocular pressure associated with postural changes are regulated by these nerves. As a result of damage to these nerves, leprosy patients lose this equilibrium in intraocular pressure and tend to have lower intraocular pressure than normal. ${ }^{6}$

So far none of these parameters have been assessed in Ethiopian patients. The purpose of this paper is:

to compare the intraoperative and postoperative complications of intracapsular cataract extraction in leprosy and nonleprosy patients;

to compare the visual outcome of intracapsular cataract extraction of leprosy and nonleprosy patients; and

to find any preoperative findings that may correlate with a poor operative outcome.

\section{Materials and methods}

All leprosy and nonleprosy patients coming for cataract extraction in the Eye Department of the All Africa Leprosy and Rehabilitation Training Centre in Addis Ababa from September 1992 to June 1993 were examined. All patients with bilateral mature cataracts and no corneal opacities in their visual axes were selected. Those with bilateral cataracts were selected because the majority of the nonleprosy patients had bilateral mature 


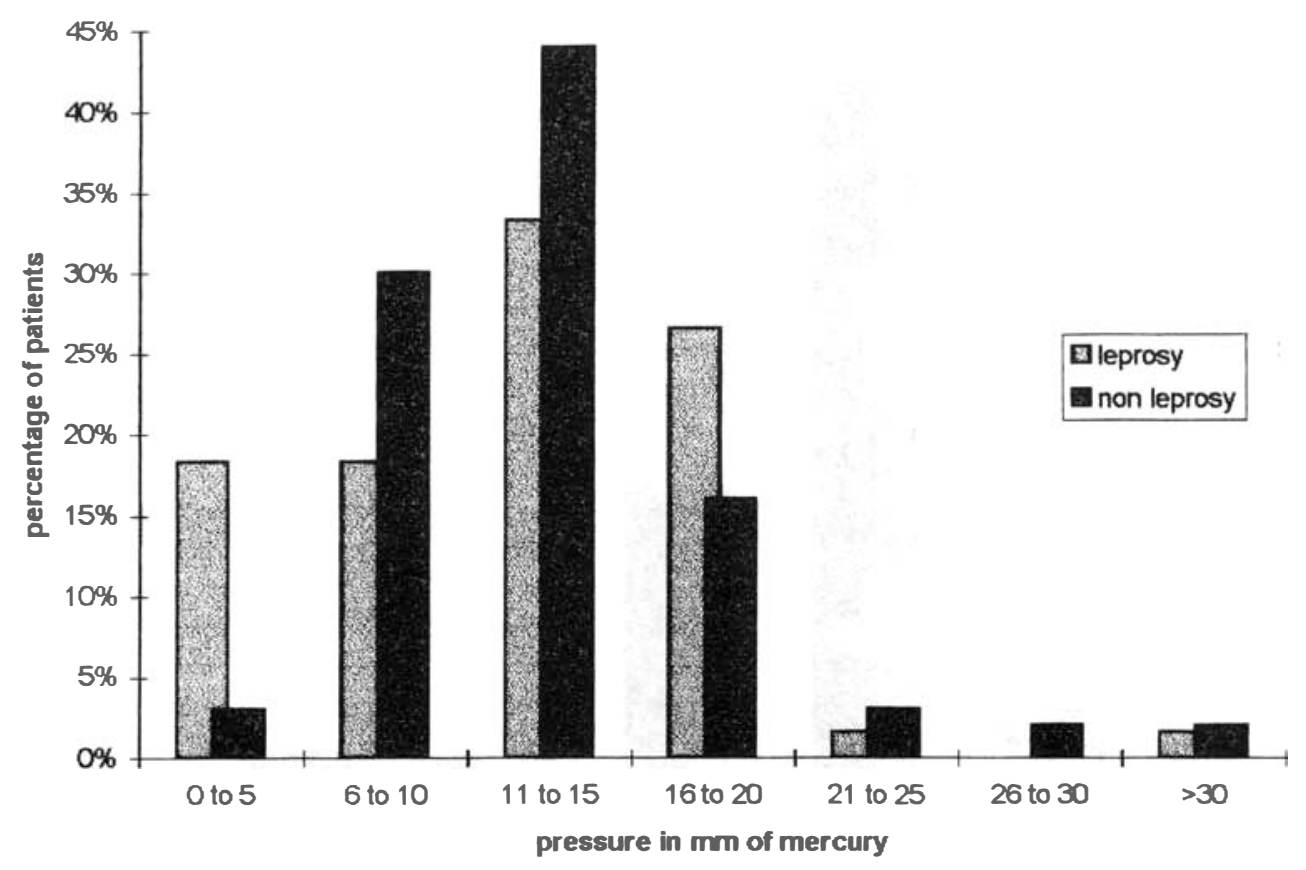

Figure 2. Post-operative intraocular pressures of leprosy and nonleprosy patients 4 weeks after operation.

cataracts (these were given priority for surgery) and we had to take leprosy patients with bilateral mature cataracts to make the groups comparable. There were 100 nonleprosy and 60 leprosy patients who fulfilled these criteria. All patients gave a history of their eye illness and underwent a general medical check-up to rule out other systemic illnesses. A thorough examination of the anterior segment and its adnexae was done using a biomicroscope. The status of the lids, the conjunctivae, the corneae, the anterior chambers, the irides, the pupils and the lenses were assessed. Intraocular pressure was measured using an applanation tonometer. The previous medical records of the leprosy patients were reviewed and duration of illness, history of recent reaction, steroid therapy, stage of treatment and leprosy classification were recorded.

Cataract extraction was done under retrobulbar anaesthesia using $2 \%$ lidocaine. A total of 160 eyes (one eye in each patient) were operated on under the microscope by three surgeons. The operations were randomly distributed amongst these three surgeons. The eyes were massaged before the operation to soften them. A fornix based conjunctival flap was made and after making a limbal groove the anterior chamber was entered, a peripheral iridectomy was done and the lens was extracted using a cryoprobe. In those with extensive posterior synechiae release was done using an iris repositor where possible and a sector iridectomy done where this was not possible. Occasionally a sphincterectomy was done in those with constricted pupils. The wound was closed with 4 to $59 / 0$ nylon sutures. Topical and subconjunctival injection of antibiotic and steroid was given intraoperatively. Topical mydriatics were applied for 2 to 3 days and stopped but steroid antibiotics were applied from the first 24 hours to when the eye irritation ceased. 
Ocular assessments were made 1 week and 1 month after operation. Visual acuity was tested using a Snellen's chart (both literate and illiterate charts were used as necessary) after giving the appropriate plus spheres by subjective refraction. Intraocular pressure measurement was done using an applanation tonometer. A thorough examination of the anterior segment was done with a biomicroscope. The anterior chamber was concentrated on and the presence of flare and keratic precipitates was observed. Subjective gradings of 1-4 were made both for flare and cells. The posterior segment was examined using a direct ophthalmoscope. All examinations were done by one individual. Masking was not possible due to the obvious physical changes in the leprosy patients.

\section{Results}

The leprosy group was mainly composed of multibacillary patients (41 (68\%)). All patients were released from treatment. Seven patients had undergone steroid therapy lasting no more than 8 weeks, 6 months before study. The male to female ratio in the leprosy group was $2 \cdot 3: 1$ while in the nonleprosy group it was $1 \cdot 5: 1$. There was a statistically significant difference between the two mean ages $(p<0 \cdot 001)$ using the $t$-test $)$.

Eight patients in the leprosy group had signs of previous uveitis. Synechiae were taken to be the only signs of a previous uveitis as the other findings could have been due to infiltration (Table 1).

In assessing the postoperative visual acuity of both groups it was found that blindness in the leprosy patients was significantly higher (relative risk 1.71 95\% confidence interval $1 \cdot 07-2 \cdot 73$ ) than in the nonleprosy patients.

There was a high rate of visual disability among leprosy patients than nonleprosy patients (Table 2) but this was not statistically significant.

The mean preoperative intraocular pressure of the leprosy group was $14.8 \mathrm{mmHg}$ and for the nonleprosy group, it was $13.8 \mathrm{mmHg}$. There were no patients with intraocular pressures of $0-5 \mathrm{mmHg}$ in either group preoperatively. The mean postoperative intraocular pressure of the leprosy group was $12.2 \mathrm{mmHg}$ and $13.2 \mathrm{mmHg}$ in the nonleprosy group. Eleven (18\%) leprosy patients had a postoperative intraocular pressure of $0-5 \mathrm{mmHg}$, while only $3(3 \%)$ of the nonleprosy group had a postoperative intraocular pressure of $0-5 \mathrm{mmHg}$. There were no specific findings in the leprosy group with low intraocular pressure.

Eighteen patients of the leprosy group had intra and postoperative complications

Table 1. Preoperative anatomical status of the anterior segment in the leprosy group

\begin{tabular}{|c|c|c|c|c|c|c|}
\hline & PB & $\%$ & MB & $\%$ & Total & $\%$ \\
\hline Iris atrophy & & & 4 & $9 \cdot 8$ & 4 & $6 \cdot 7$ \\
\hline Anterior and posterior synechiae & & & 8 & $19 \cdot 6$ & 8 & $13 \cdot 3$ \\
\hline Lagophthalmos with exposure keratitis & 1 & $5 \cdot 3$ & 1 & $2 \cdot 4$ & 2 & $3 \cdot 3$ \\
\hline Constricted pupil & & & 2 & $4 \cdot 9$ & 2 & $3 \cdot 3$ \\
\hline Iris holes & & & 1 & $2 \cdot 4$ & 1 & $1 \cdot 7$ \\
\hline No major abnormalities & 18 & $94 \cdot 7$ & 25 & $60 \cdot 9$ & 43 & $71 \cdot 7$ \\
\hline Total & 19 & 100 & 41 & 100 & 60 & 100 \\
\hline
\end{tabular}


Table 2. Postoperative visual acuity with +10 sphere correction 1 month after operation

\begin{tabular}{lcccr}
\hline Post-operative visual acuity & Leprosy & $\%$ & Nonleprosy & $\%$ \\
\hline Blind (light perception-<3/60) & 9 & 15 & 6 & 6 \\
Visually disabled $(3 / 60-6 / 60)$ & 22 & $36 \cdot 7$ & 36 & 36 \\
Not visually disabled $(6 / 36-6 / 9)$ & 29 & $48 \cdot 3$ & 58 & 58 \\
\hline Total & 60 & 100 & 100 & 100 \\
\hline
\end{tabular}

while only 6 patients of the nonleprosy group had complications. This was statistically significant (relative risk, 1.8 for $95 \%$ confidence interval $1.06-4 \cdot 37 p=0 \cdot 0409$ ). Out of the 18 leprosy patients, 7 were paucibacillary and 11 were multibacillary. Out of 11 multibacillary cases 5 had iris changes. The rate of complications was much higher in the paucibacillary group (Table 3 ).

Anterior chamber reaction was also assessed and it was found that the difference in anterior chamber reaction between the two groups was not statistically significant.

\section{Discussion}

The leprosy group had a higher rate of intra and postoperative complications. Out of these leprosy patients, the paucibacillary group had a higher rate of complications. This is different from similar studies done in India and Korea. ${ }^{4,7,9,10}$ The small sample group may have contributed to this proportion of complications and things may be different if the sample was much larger. If we look into the complications that the paucibacillary group underwent they were: vitreous loss, capsular rupture and secondary glaucoma. These complications may not be necessarily due to uveal infiltration. Thus one may need to define complications as those with a possible association with ocular infiltration and inflammation and those without, and it may turn out that the multibacillary may have higher rates of infiltration-associated complications.

The blindness rate and the overall visual disability was much higher in leprosy patients. This is not similar to other studies done in India and Liberia. ${ }^{8,9,11}$ This may have been due to corneal decompensation following an operation incision as this reduces the corneal

Table 3. Intra and postoperative complications in leprosy and nonleprosy patients

\begin{tabular}{|c|c|c|c|c|c|c|}
\hline \multirow[b]{2}{*}{ Complications } & \multicolumn{4}{|c|}{ Leprosy } & \multicolumn{2}{|c|}{ Nonleprosy } \\
\hline & PB & $\%$ & MB & $\%$ & & $\%$ \\
\hline Vitreous loss & 3 & $15 \cdot 8$ & 4 & $9 \cdot 7$ & 6 & 6 \\
\hline Secondary glaucoma & 1 & $5 \cdot 2$ & 2 & $4 \cdot 9$ & 1 & 1 \\
\hline Retinal detachment & & & & & 1 & 1 \\
\hline Vitreous haemorrhage & & & 2 & $4 \cdot 9$ & 2 & 2 \\
\hline Capsular rupture & 3 & $15 \cdot 8$ & 3 & $7 \cdot 3$ & 6 & 6 \\
\hline Total & 7 & $36 \cdot 8$ & 11 & $26 \cdot 8$ & 16 & 16 \\
\hline
\end{tabular}


sensation markedly exposing the cornea to microtrauma and cell death due to the lack of innervation. This can result in corneal damage and astigmatism leading to impaired vision.

All patients had a comparable density of cataract before operation, all the layers of the lens were opaque. However the patients in the leprosy group were younger than those in the nonleprosy group. One can make several speculations on the earlier occurrence of cataract in leprosy patients. According to Prabhakaran Mycobacterium leprae produce tyrosinase which oxidizes DOPA to quinones and these attach to proteins in the lens and cause opacification. ${ }^{13}$ As most of our leprosy patients were multibacillary cases this increases the chance of $M$. leprae being in the ocular tissues. Thus one can speculate that leprosy could have been the cause of early cataract formation. ${ }^{4}$ Repeated inflammation in leprosy can also cause early development of cataract. ${ }^{4,12}$

Seventy percent of the nonleprosy patients were paying for their treatment while all the leprosy patients were non-paying. Thus the nonleprosy patients could have remained longer with their cataracts before coming for treatment due to economic reasons. The majority of the leprosy patients were beggars thus the chances of these patients being well nourished are quite low, and their exposure to the sun is quite high. Thus malnutrition and sun exposure could have contributed to the early development of cataract. ${ }^{14}$

Steroids are the other factor that can contribute to cataract formation but only very few patients had had a course of steroid during their treatment and the courses were quite short.

Similar to other studies, there were a significant number of leprosy patients who had a low intraocular pressure. ${ }^{5}$ This may have been due to the already compromised state of the ciliary body plus the operative trauma resulting in decreased aqueous production. ${ }^{5}$ Autonomic nerve damage may have also contributed to the instability of the intraocular pressure. ${ }^{6}$ The low intraocular pressure could not be correlated to any preoperative findings.

Cataract occurred early in the leprosy group in our study and larger studies must be done on a larger number of patients to confirm this observation. Intracapsular cataract extraction was associated with a higher rate of visual disability and care must be taken when doing this procedure. Unlike previous beliefs, intra- and postoperative complications in leprosy patients should not be associated with uveal changes only.

\section{Acknowledgment}

We would like to thank Professor James Hanley of the Mcgill Group Addis Abeba for doing the statistical analyses and the staff of the Eye Department, ALERT for their continuous cooperation.

\section{References}

${ }^{1}$ Hogeweg M, Faber WR. Progression of lesions in leprosy ten years follow-up study in the Netherlands. Int J Lepr, 1991; 59: 392-397.

2 Mehra V, Minassian DC. A rapid method of grading cataract in epidemiological studies and eye surveys. Brit J Ophthalmol, 1988; 72: 801-803.

3 Evans J, Minassian DL. Epidemiology of age related cataract. Community Eye Health Bull, 1992; 9: 2-6.

4 Brandt F, Kampik A, Pok OK, Hard RP. Blindness from cataract formation in leprosy. Developments in Ophthalmology, Vol. 7, pp. 1-22. (Krager Basel 1983). 
${ }^{5}$ Brandt F, Malla DK, Anten JGF. Influence of untreated chronic plastic iridocyclitis on intraocular pressure in leprosy patients. Br J Ophthalmol, 1981; 65: 240-42.

${ }^{6}$ Lewallen S, Hussein N, Courtright P, Ostler B, Geiber R. Intraocular pressure and iris denervation in Hansen's Disease. Int J Lepr, 1990; 58: 39-44.

${ }^{7}$ Ffytche TJ. Cataract Surgery in the management of late complications of lepromatous leprosy in South Korea. Br J Ophthalmol, 1981; 65: 243-48.

${ }^{8}$ Rao VA, Kwatra VK. Cataract extraction in leprosy patients. Lepr Rev, 1988; 59: 67-70.

9 Suryanwashi N, Richard J. Cataract surgery in leprosy patients. Int J Lepr, 1988; 56: 238-42.

10 Namperumalswamy P, Das T. Surgical treatment of complicated cataract following chronic uveitis. Ind $J$ Ophthalmol, 1982; 30: 87-89.

${ }_{11}^{11}$ Frucht-Pery J, Feldman ST. Cataract surgery in leprosy patients. Int J Lepr, 1993; 61: 21-24.

${ }_{12}$ Somerset EJ, Sen NJ. Prognosis of ocular lesions of leprosy. Lepr India, 1957; 29: 142-147.

${ }_{13}$ Prabhakaran K. Cataract in Leprosy; a biochemical approach. Lepr Rev, 1979; 12: 11-13.

14 Minassian DC, Mehra V, Jones Br. Dehydrational crises from severe diarrhoea and or heat stroke and risk of cataract. Lancet, 1984; 1: 751-753. 